\title{
Electrical and Optical Properties of Ternary System of Bi-Sb-Se
}

\author{
M. S. Abo Ghazala1, A. H. Ammar ${ }^{2}$ and A. Eleskandrany ${ }^{3}$ \\ ${ }^{1}$ Physics department, Faculty of Science, Menoufia University, Sheben \\ El-Koom, Egypt. \\ ${ }^{2}$ Physics department, Faculty of Education, Ain Shams University, \\ Cairo, Egypt \\ ${ }^{3}$ Physics department, Faculty of Science, Taiz University, Taiz, Yemen
}

Polycrystalline alloys of $B i_{48-x} S_{x} S e_{52}$ (where $x=0.6,11,25,35$ and 44 at. \%) have been prepared by direct fusion technique. The crystalline nature has been identified using X-ray diffraction. The electrical measurements of $d c$ and ac conductivities as well as the infrared transmittance were investigated. Compositional dependences of electrical conductivity and the absorption edge are discussed from the stand point of chemical bonds formed in alloys and related to changes of the free charge carriers concentration (Moss - Burstein effect) and ionicity due to incorporation of Sb atoms in high concentrations. The data of the UV/VIS spectroscopy showed that the mechanism of the optical absorption followed the rule of allowed direct transition for all compositions.

\section{Introduction:}

Ternary compound semiconductors are currently being investigated due to their variety of applications in thermoelectric devices at room temperature, photovoltaic solar cell materials, electro- optics, opto-electronics and non-linear optics. Solid solutions based on bismuth and antimony chalcogenides find a wide range of thermoelectric applications now as high-efficiency devices [1-3]. Candidate materials for thermoelectric applications should possess high electrical conductivity, high Seebeck coefficient, and low thermal conductivity. Considerable attention have been devoted to the research of $\mathrm{Bi}_{2} \mathrm{Se}_{3}$ [4,5]. Some studies on optical and electrical conductivity measurements of the single crystals $\left(\mathrm{Bi}_{1-\mathrm{x}} \mathrm{Sb}_{\mathrm{x}}\right)_{2} \mathrm{Se}_{3}$ for $\mathrm{x}=0$ to 0.2 have been reported [6,7]. In this article the compositional dependence of the electrical conductivity and the optical energy gap of $\mathrm{Bi}_{48-\mathrm{x}} \mathrm{Sb}_{\mathrm{x}} \mathrm{Se}_{52}$ (where $\mathrm{x}=0.6,11,25,35$ and 44 at.\%) polycrystalline alloys is discussed. 


\section{Experimental:}

Polycrystalline alloys of $\mathrm{Bi}_{48-\mathrm{x}} \mathrm{Sb}_{\mathrm{x}} \mathrm{Se}_{52}$ (where $\mathrm{x}=0.6,11,25,35$ and 44 at.\%) have been prepared by direct fusion technique. Proper amounts of Sb, Bi and Se ( purity $99.999 \%$ ) were mixed together and put in silica tubes which are then sealed off at vacuum $\approx 10^{-5}$ Torr. The sealed ampoules were inserted in an electric furnace held at $1173 \mathrm{~K}$ for $24 \mathrm{~h}$. During the course of heating, the tubes were shaken vigorously at regular intervals to ensure homogeneity of the alloys. The tubes were then cooled gradually to room temperature. Five specimens of as-prepared samples were ground up and put onto ultrasonically cleaned glass substrates to be examined using X-ray diffractometer, type, [X" PERT-MPDUG (Philips PW 1370)] to confirm the morphology and crystalline nature of materials. The results of energy dispersive X-ray (EDX) confirmed the presence of $\mathrm{Sb}, \mathrm{Bi}$ and $\mathrm{Se}$ in the proper amounts and no other impurities exist.

The infrared data was recorded at normal incidence in the wavelength range 2.5-25 $\mu \mathrm{m}$ by means of Fourier Transform Infrared Spectrometer [Jasco FT/IR- 410]. The data of transmittance (T) and absorbance (A) were determined at normal incidence in the wavelength range $0.3-1.1 \mu \mathrm{m}$ by means of double-beam UV/VIS spectrophotometer (SPECORD 40/analytik-jena).

An electrometer (Keithly 6517A) was used for measuring the electrical conductivity by measuring the electrical resistance of each specimen which fabricated in the disk form of $1 \mathrm{~cm}$ diameter and $3 \mathrm{~mm}$ thickness. The specimen was held between two graphite electrodes (as pressure contact to it) in a copper holder. The sample holder was placed in an electric furnace in which the temperature was varied by heating rates $1 \mathrm{~K} / \mathrm{min}$ using a temperature controller. The dielectric properties were measured using a bridge (type INSTEK-LCR 821 ) in the frequency range $10^{2}-2 \times 10^{5} \mathrm{~Hz}$. The cross-linked samples were in the form of disks of range 0.156 to $0.262 \mathrm{~cm}$ thick. The samples were sandwiched between two brass electrodes and both their capacitance and their dielectric loss tangent $(\tan \delta)$ values were measured at different frequencies. The dielectric constant $\varepsilon^{\prime}$ (real part of the dielectric constant) of the samples and the a.c conductivity $\sigma_{\mathrm{ac}}$ were calculated by using the relations:

$$
\begin{gathered}
\varepsilon^{I}=\frac{\mathrm{d}}{\varepsilon \cdot \mathrm{A}} \mathrm{C} \\
\sigma_{\mathrm{ac}}=\omega \varepsilon_{\diamond} \varepsilon^{I I} \\
\varepsilon^{I I}=\varepsilon^{I} \tan \delta
\end{gathered}
$$


where $\mathrm{C}$ is the capacitance, $\mathrm{d}$ is the thickness of the sample and $\mathrm{A}$ is the crosssectional area of each of the parallel surface of the sample. $E_{\infty}$ is the permittivity of free space $\left(8.85 \times 10^{-12} \mathrm{~F} / \mathrm{m}\right), \varepsilon^{I I}$ is the dielectric loss ( imaginary part of the dielectric constant) and $\omega$ is the angular frequency $(\omega=2 \pi f)$.

\section{Results and Discussion:}

\subsection{X-ray Diffraction:}

$\mathrm{X}$-ray diffraction patterns of as-deposited $\mathrm{Bi}_{48-\mathrm{x}} \mathrm{Sb}_{\mathrm{x}} \mathrm{Se}_{52}$ (where $\mathrm{x}=0.6$, $11,25,35$ and 44 at. \%) alloys were recorded at room temperature. The crystalline phases of the alloys were detected from the corresponding peaks appeared in the X-ray patterns as shown in Fig. (1) which indicate that the alloys are polycrystalline in nature. The analysis of the diffraction pattern according to the ASM cards showed that the phases appeared are rhombohedral $\left(\mathrm{Bi}_{2} \mathrm{Se}_{3}, \mathrm{Bi}\right.$ and $\left.\mathrm{Sb}\right)$, orthorhombic $\left(\mathrm{Sb}_{2} \mathrm{Se}_{3}\right)$ and monoclinic $(\mathrm{Se})$. It is seen that with increasing the $\mathrm{Sb}$ content, the peak intensity corresponding to the $\mathrm{Sb}_{2} \mathrm{Se}_{3}$ and $\mathrm{Sb}$ phases increases while that corresponding to $\mathrm{Bi}_{2} \mathrm{Se}_{3}$ phases decreases sharply. This indicate that the $\mathrm{Sb}_{2} \mathrm{Se}_{3}$ phases grows in the matrix at the expense of $\mathrm{Bi}_{2} \mathrm{Se}_{3}$ phases as the $\mathrm{Sb}$ content increases.

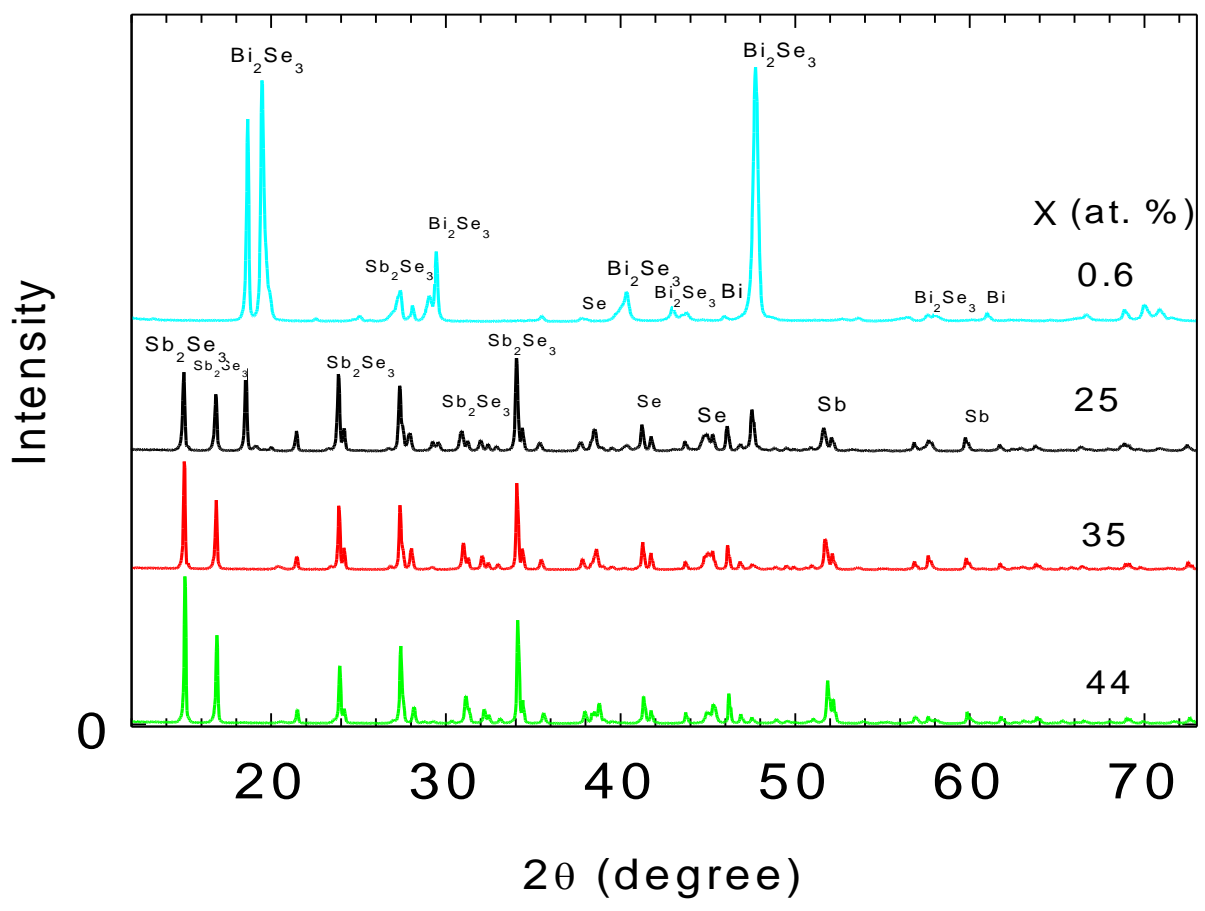

Fig. (1): X-ray diffraction patterns of $\mathrm{Bi}_{48-\mathrm{x}} \mathrm{Sb}_{\mathrm{x}} \mathrm{Se}_{52}$ alloys. 


\subsection{Electrical Properties:}

\subsubsection{Conductivity:}

Figure (2) show the temperature dependence of the d.c conductivity for the $\mathrm{Bi}_{48-\mathrm{x}} \mathrm{Sb}_{\mathrm{x}} \mathrm{Se}_{52}$ (where $\mathrm{x}=0.6,11,25,35$ and 44 at. \%), in the temperature range $303-393 \mathrm{~K}$. All the curves show straight lines for the plots of $(\ln \sigma)$ vs. $(1 / \mathrm{T})$ obeying the relation:

$$
\sigma_{\mathrm{d}}=\sigma_{\diamond} \mathrm{e}^{-\mathrm{E}_{\mathrm{a}} / \mathrm{kT}}
$$

where $E_{a}$ is the activation energy, $k$ is the Boltzmann's constant, while $\sigma_{o}$ is constant.

The results exhibit only one type of conduction mechanism in the temperature range $303-393 \mathrm{~K}$ for all compositions. This mechanism is regarded as a regular band - type conduction in the localized states. The activation energy of conduction and dc conductivity measured at $303 \mathrm{~K}$ are summarized in table 1 for all compositions. It is seen that the dark conductivity increases up to $\mathrm{x}=11$ at. $\%$ and then decreases with increasing the Sb content, while the activation energy changes with $\mathrm{Sb}$ content in an opposite manner.

Table (1): The values of $0_{303 \mathrm{~K}}$ and $\mathrm{E}_{\mathrm{a}}$ for $\mathrm{Bi}_{48-\mathrm{x}} \mathrm{Sb}_{\mathrm{x}} \mathrm{Se}_{52}$ alloys.

\begin{tabular}{|c|c|c|c|}
\hline Sample No. & Composition(x) at.\% & $\mathrm{E}_{\mathrm{a}}(\mathrm{eV})$ & $\sigma_{303 \mathrm{~K}}\left(\Omega^{-1} \mathrm{~cm}^{-1}\right)$ \\
\hline A4 & 0.6 & 0.085 & 0.04 \\
\hline A12 & 11 & 0.029 & 0.12 \\
\hline A20 & 25 & 0.188 & 0.004 \\
\hline A28 & 35 & 0.478 & $1.33 \mathrm{E}-6$ \\
\hline A36 & 44 & 0.523 & $7.80 \mathrm{E}-5$ \\
\hline
\end{tabular}

For single crystals of $\left(\mathrm{Bi}_{1-\mathrm{x}} \mathrm{Sb}_{\mathrm{x}}\right)_{2} \mathrm{Se}_{3}$ solid solutions $(\mathrm{x}=0-0.2)$ [7], it has been reported that the incorporation of the antimony atoms in $\mathrm{Bi}_{2} \mathrm{Se}_{3}$ crystal lattice results in an increase of the free electron concentration for low antimony content, whereas the free electron concentration is suppressed in the range of high antimony content [7]. In agreement, for the system $\mathrm{Bi}_{48-\mathrm{x}} \mathrm{Sb}_{\mathrm{x}} \mathrm{Se}_{52}$ under study, the measurements showed an increase in conductivity for $\mathrm{x}=0.6$ and 11 at. $\%$ and a decrease in conductivity for higher antimony concentration. This means that the free electron concentration decreases with rising the $\mathrm{Sb}$ content from 25 up to $\mathrm{x}=44$ at. $\%$. 


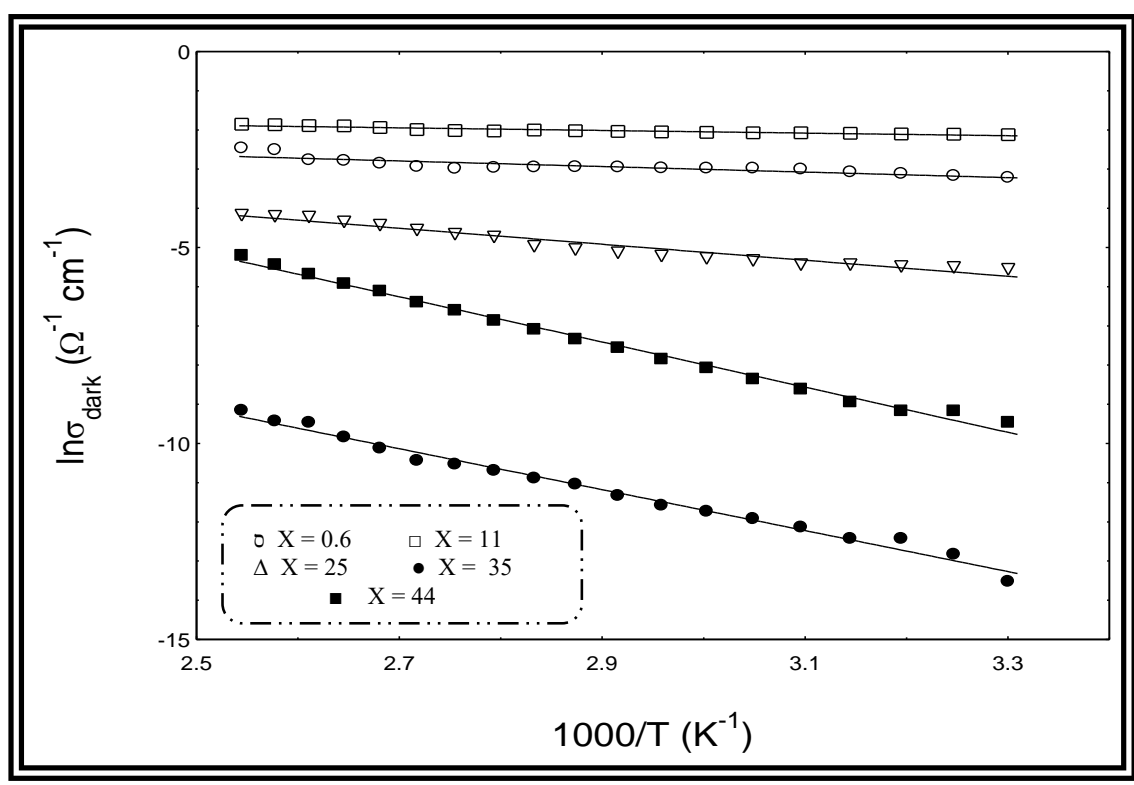

Fig. (2): Temperature dependence of the dark conductivity $\sigma_{\mathrm{dc}}$ for the $\mathrm{Bi}_{48-\mathrm{x}} \mathrm{Sb}_{\mathrm{x}} \mathrm{Se}_{52}$ bulk alloys.

\section{2.2. A.C conductivity Measurements:}

The plot of a.c. conductivity as a function of frequency for the system $\mathrm{Bi}_{48-\mathrm{x}} \mathrm{Sb}_{\mathrm{x}} \mathrm{Se}_{52}$, where $\mathrm{x}=0.6,25,35$ and 44 at.\% is illustrated in Fig. (3). It is seen that the a.c. conductivity is decreased with rising the frequency for all compositions, except for $\mathrm{x}=44$ at. $\%$, it seems to be constant.

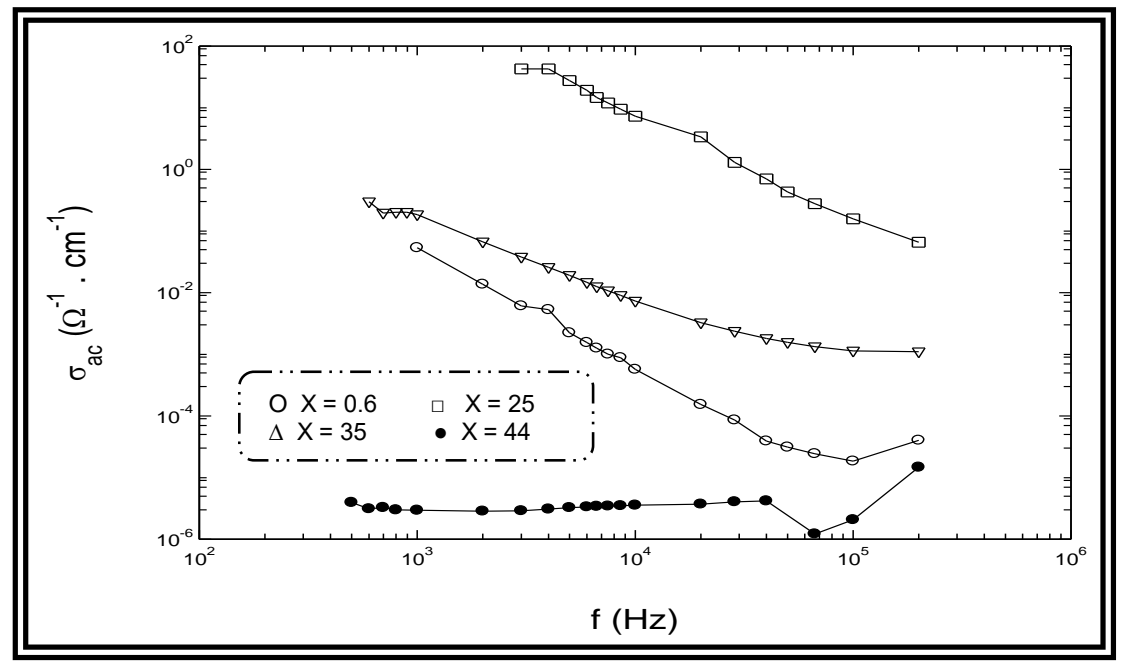

Fig. (3): AC conductivity vs. the frequency for $\mathrm{Bi}_{48-x} \mathrm{Sb}_{x} \mathrm{Se}_{52}$ alloys. 
The frequency dependence of the dielectric constant $\varepsilon^{\prime}$ and dielectric loss $\varepsilon^{\prime \prime}$ are shown in Figs. (4 and 5), respectively. It can be observed that all curves obtained for the system $\mathrm{Bi}_{48-\mathrm{x}} \mathrm{Sb}_{\mathrm{x}} \mathrm{Se}_{52}$, where $\mathrm{x}=0.6,25,35$ and 44 at.\% show that $\varepsilon^{\prime}$ and $\varepsilon^{\prime \prime}$ decrease almost linearly with increasing the frequency in the range $10^{3}-10^{5} \mathrm{~Hz}$ and remain almost constant at higher frequencies. One can conclude that the real and imaginary components increase indefinitely as frequency is lowered. This means that the low frequency dispersion of the $\mathrm{Bi}_{48-}$ ${ }_{x} \mathrm{Sb}_{x} \mathrm{Se}_{52}$ alloys arise mainly from the localized charge carrier conduction, which is characterized by free electron transport mechanism. It is seen also that $\varepsilon^{\prime}$ and $\varepsilon^{\prime \prime}$ increase in the beginning with rising the Sb content up to $\mathrm{x}=25$ at.\% and then decrease for high concentration of Sb content. This behavior is related to change of the free carrier concentration upon change the antimony concentration [7]. As mentioned above an increase of the free electron concentration is dominated for low antimony content, whereas it is suppressed in the range of high antimony content.

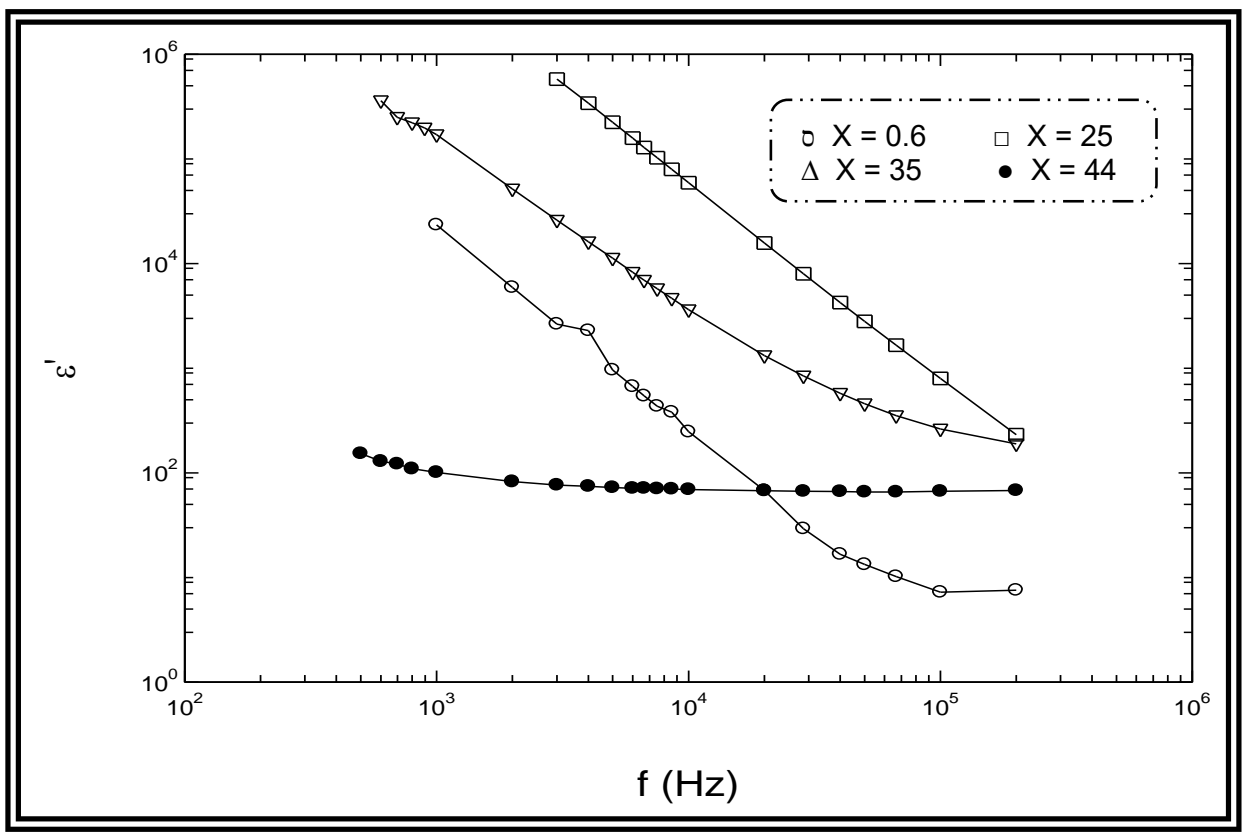

Fig. (4): Real part of dielectric constant vs. frequency for $\mathrm{Bi}_{48-\mathrm{x}} \mathrm{Sb}_{\mathrm{x}} \mathrm{Se}_{52}$ alloys. 


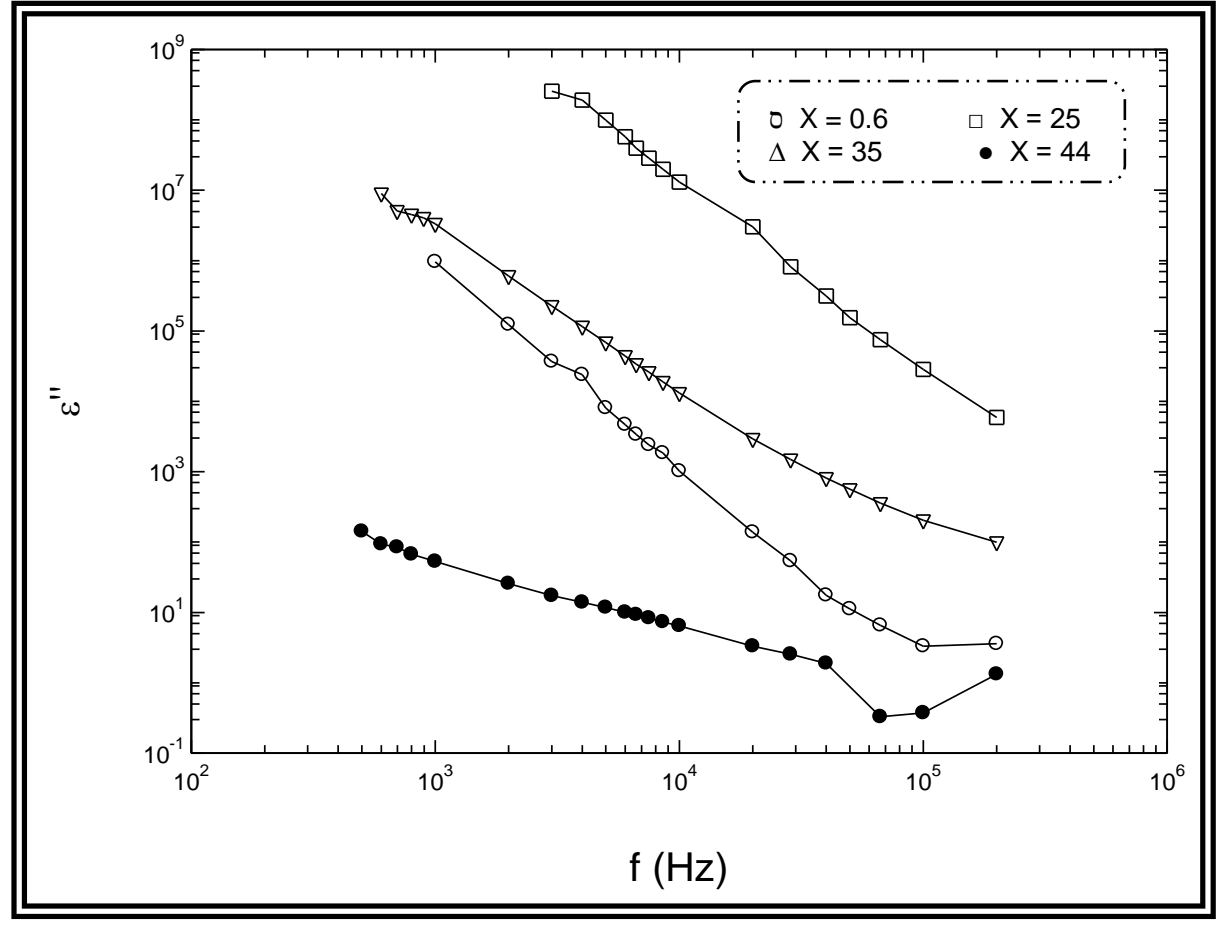

Fig.(5): Imaginary part of dielectric constant vs frequency for $\mathrm{Bi}_{48-x} \mathrm{Sb}_{x} \mathrm{Se}_{52}$ alloys

\subsection{Optical properties:}

\subsubsection{Effect of Composition on the Absorption of IR Radiation:}

Figure (6) illustrates the spectral behavior of the observed IR transmittance of the polycrystalline $\mathrm{Bi}_{48-\mathrm{x}} \mathrm{Sb}_{\mathrm{x}} \mathrm{Se}_{52}$ alloys, where $\mathrm{x}=0.6,11,25$, 35 and 44 at. $\%$ in the wavelength range $2.5-25 \mu \mathrm{m}$. It is shown that the general behavior of the spectra depends on the composition.

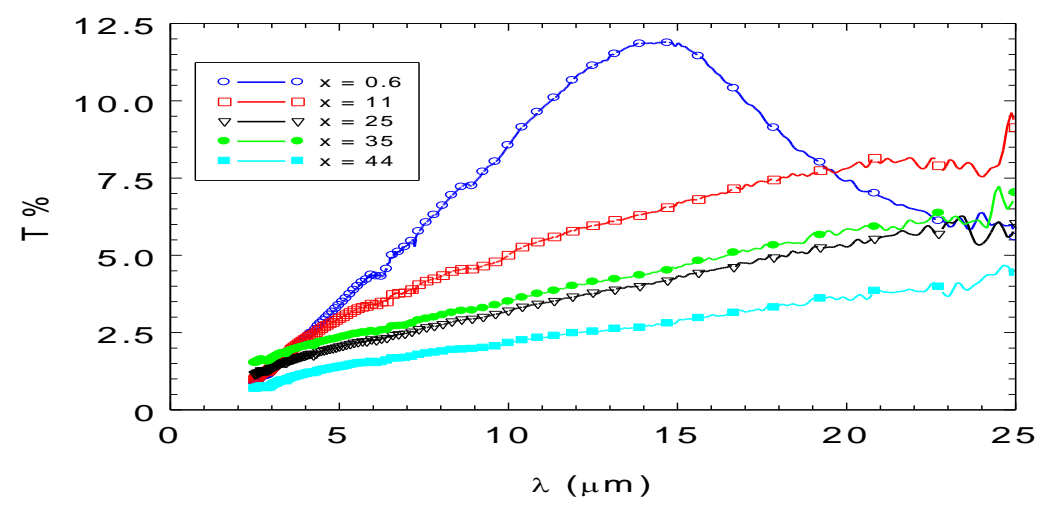

Fig. (6): IR Spectral distribution of $\mathrm{T}(\lambda)$ for crystalline $\mathrm{Bi}_{48-\mathrm{x}} \mathrm{Sb}_{\mathrm{x}} \mathrm{Se}_{52}$ alloys. 
Figure (7) shows the variation of the absorption coefficient $\alpha$ as a function of photon energy ( $h v$ ) for the $\mathrm{Bi}_{48-\mathrm{x}} \mathrm{Sb}_{\mathrm{x}} \mathrm{Se}_{52}$ alloys. It is seen that, in the photon energy range $0.1-0.3 \mathrm{eV}, \alpha$ almost increases as the $\mathrm{Sb}$ content increases.

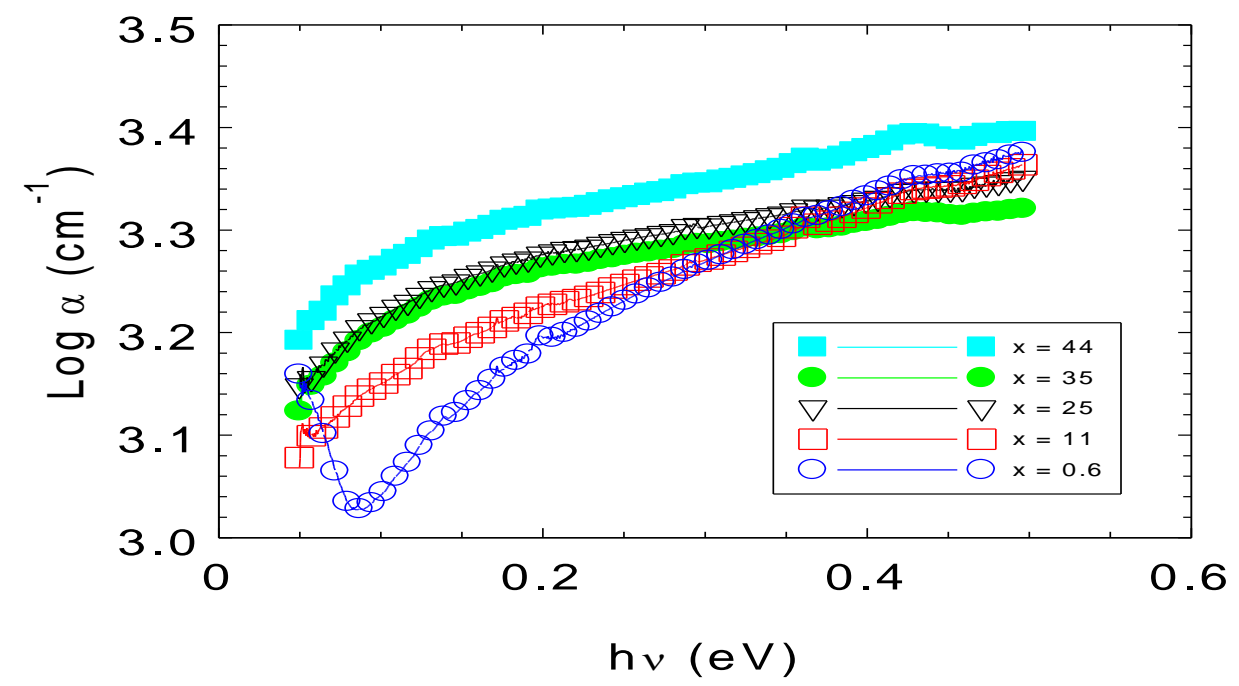

Fig. (7): Variation of the absorption coefficient $(\alpha)$ of $\mathrm{Bi}_{48-\mathrm{x}} \mathrm{Sb}_{\mathrm{x}} \mathrm{Se}_{52}$ alloys with the photon energy (hv).

Below a certain photon energy (about $0.2 \mathrm{eV}$ ), $\alpha$ decreases sharply for all compositions of the system. It is known that near the fundamental absorption edge, the absorption coefficient varies rapidly with frequency.

The shape of the long-wavelength edge gives information on the scattering mechanism of the free charge carriers. For the propose to determine the values of the exponent $\mathrm{b}$ in the relation: $\alpha \sim \lambda^{b}$, the plot of $\ln \alpha$ versus $\ln \lambda$ shown in Fig. (8) gives $b=0.63$ for $\mathrm{x}=0.6$ at. $\%$ which is less than 1.5 and the exponent $\mathrm{b}$ vanishes for other compositions with higher values of $\mathrm{Sb}$ content. It has been reported that in $\left(\mathrm{Bi}_{1-\mathrm{x}} \mathrm{Sb}_{\mathrm{x}}\right)_{2} \mathrm{Se}_{3}$ crystals $(\mathrm{x}=0$ to 0.2$)$ at temperature close to $300 \mathrm{~K}$ the dominant scattering mechanism of the free carriers is the scattering by acoustic branches of lattice vibrations [6]. This type of scattering takes place for only one composition ( $\mathrm{x}=0.6$ at.\%) of the $\mathrm{Bi}_{48-\mathrm{x}} \mathrm{Sb}_{\mathrm{x}} \mathrm{Se}_{52}$ system. 


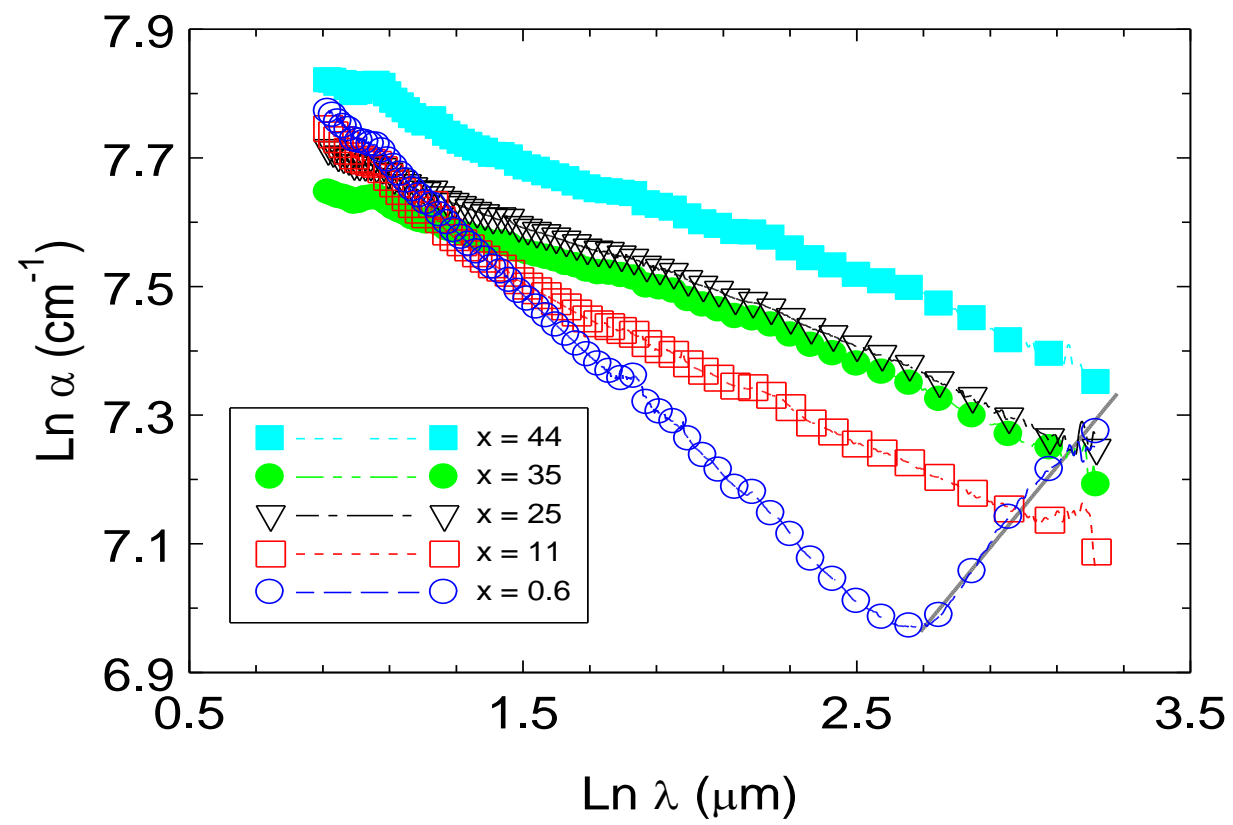

Fig. (8): Plots of $\ln \alpha$ vs. $\ln \lambda$ for polycrystalline $\mathrm{Bi}_{48-\mathrm{x}} \mathrm{Sb}_{x} \mathrm{Se}_{52}$ alloys.

\subsubsection{Compositional dependence of the optical energy gap}

The spectral dependence of the transmittance $(T)$ of the polycrystalline $\mathrm{Bi}_{48-\mathrm{x}} \mathrm{Sb}_{\mathrm{x}} \mathrm{Se}_{52}$ alloys was measured in the wavelength range 0.32-1.1 $\mu \mathrm{m}$ with normal incidence of light at room temperature. The absorption in semiconductors is characterized by Tauc`s relation:

$$
\alpha h v=A\left(h v-E_{g}\right)^{n}
$$

where $\mathrm{A}$ is a constant, $\alpha$ is the absorption coefficient, $\mathrm{E}_{\mathrm{g}}$ is the optical energy gap of the studied materials and the exponent $\mathrm{n}$ characterize the transition type. This is the usual method to determine exactly the transition type. Fig. (9) shows the plots of $(\alpha h v)^{2}$ versus $h v$ for the $\mathrm{Bi}_{48-\mathrm{x}} \mathrm{Sb}_{\mathrm{x}} \mathrm{Se}_{52}$ alloys (where $\mathrm{x}=0.6,11,25$, 35 and 44 at.\%) indicating that the transition is allowed direct transition. 


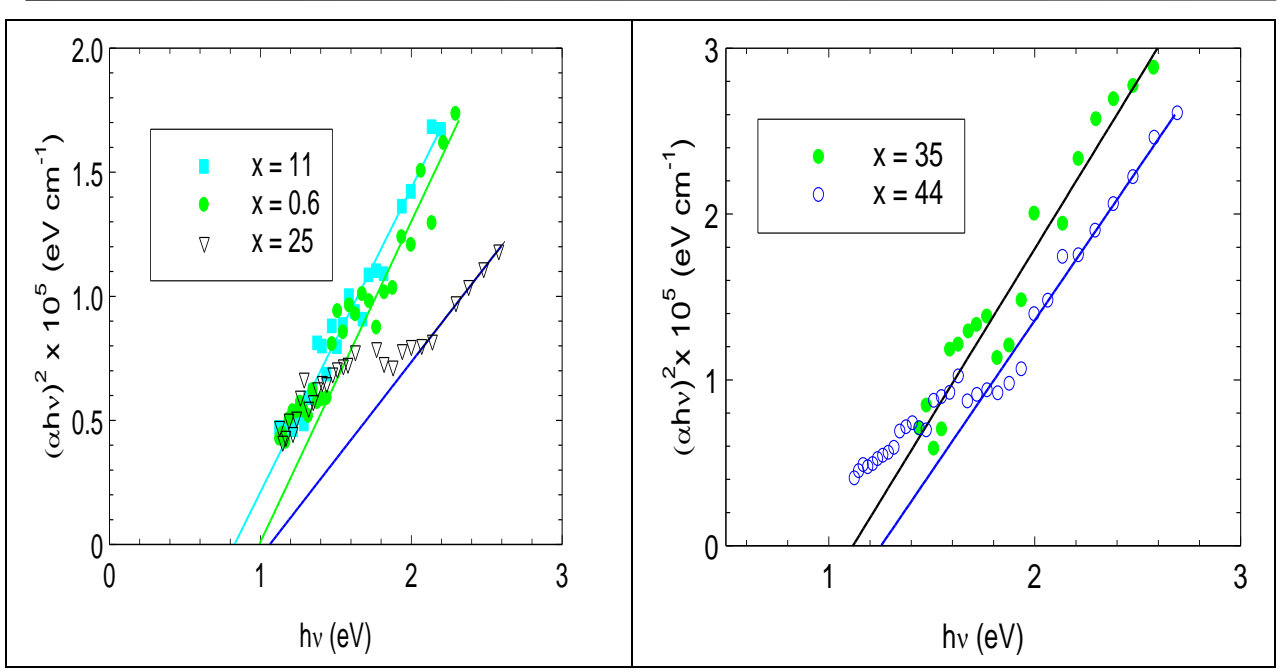

Fig. (9): Plots of $(\alpha h v)^{2}$ versus hv for the system $\mathrm{Bi}_{48-\mathrm{x}} \mathrm{Sb}_{\mathrm{x}} \mathrm{Se}_{52}$.

The dependence of the optical energy gap $\mathrm{E}_{\mathrm{g}}$ of the $\mathrm{Bi}_{48-\mathrm{x}} \mathrm{Sb}_{\mathrm{x}} \mathrm{Se}_{52}$ alloys on composition $\mathrm{x}$ is shown in Fig. (10). There are two factors affecting the optical energy gap. One of them is related to the Moss - Burstein effect in which an increase in the free carrier concentration $\mathrm{N}$ leads to a shift of the edge towards higher energies whereas a decrease in the value of $N$ give rise to a shift of the absorption edge towards lower energies. The second factor is the variation of the ionicity of the crystal which showed that the substitution of $\mathrm{Sb}$ atoms for $\mathrm{Bi}$ in the $\mathrm{Bi}_{2} \mathrm{Se}_{3}$ crystal lattice results in an observable increase of the optical gap $E_{g}$ [6] (where the value of $\mathrm{E}_{\mathrm{g}}$ for $\mathrm{Bi}_{2} \mathrm{Se}_{3}$ is $0.115 \mathrm{eV}$ [8] and for $\mathrm{Sb}_{2} \mathrm{Se}_{3}$ is $1.2 \mathrm{eV}$ [9]). Our results reveal that the action of ionicity effect is dominant. In samples with lowest $\mathrm{Sb}$ content $(\mathrm{x}=0.6$ and 11 at.\%) the free carrier concentration increases as discussed above (section 3.2.1) but the energy gap was found to decrease where as in the samples with high $\mathrm{Sb}$ content $(x=25,35$ and 44 at. \%) the optical gap is increased with rising the Sb content due to the increase in the ionicity. In general the variation of the activation energy of conduction with the composition is similar with that of the optical energy gap. This variation is related to change of the free carrier concentration as well as the variation of the ionicity. 


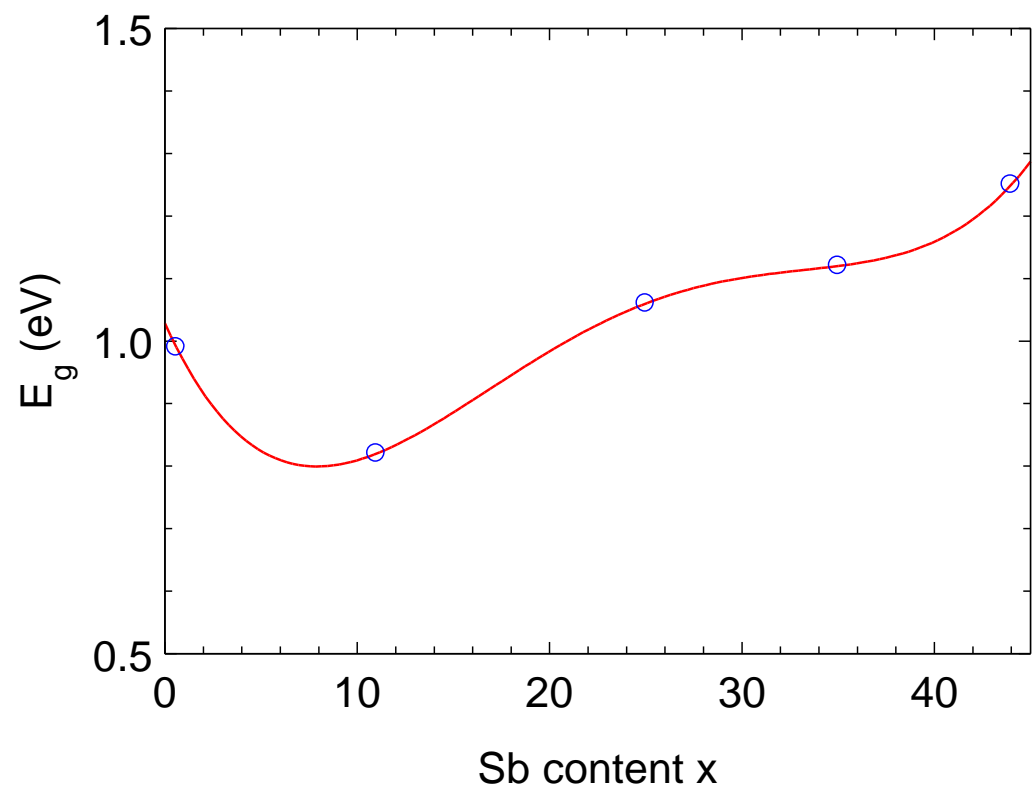

Fig. (10): The variation of the optical energy gap $E_{g}$ as a function of composition $\mathrm{Bi}_{48-\mathrm{x}} \mathrm{Sb}_{\mathrm{x}} \mathrm{Se}_{52}$ alloys

\section{References:}

1. A.F. Semizorev, Inorganic Materials, 316, 675 (1995).

2. T.E. Svechnikova, L.E. Shelimova, P. P. Konstantinov, M. A. Kretova, E.S. Avilov, V.C. Zemskov, Kh. Shtive, A. Zuber, Müller E. Inorganic. Mater., 41(10), 1186 (2005).

3. V.A. Kutasov, L.N. Lukyanova, M.V. Vedernikov, Thermoelectrics Handbook Macro to Nano. Ed, by D.M. Rowe, CRC, Taylor \& Francis Group, (2006).

4. B. Pejova, I. Grozdanov, and A. TanuŠevski, Materials Chem. and Phys., 83, 245 (2004).

5. S. Augustine, S. Ampili, J. Ku Kang, and E. Mathai, Mater. Res. Bull., 40, 1314 (2005).

6. J. Navratil, P. Lostak, C. Drasar, and T. Blachut, phys. stat. sol., (b) 194, 783 (1996).

7. P. Lostak, Č. Drašar, H. Sussmann, P. Reinshaus, R. Novotny, and L. Benes, J. Cryst. Growth, 179, 144 (1997).

8. H. Kohler and J. Hartmann, Phys. Stat. Sol., (b) 63, 171 (1974).

9. J. Black, E. M. Conwell, L. Skigle and C. W. Spencer, J. Phys. Chem. Solids, 2, 240 (1957). 